\title{
Deteç̧ão de metais potencialmente tóxicos em biofilme e água de ambiente lótico
}

Os biofilmes tem se mostrado bons monitores de contaminação por metais, pois fornecem respostas rápidas as alterações ambientais. Diante disso, objetivou-se nesse estudo avaliar a concentração dos metais $\mathrm{Al}, \mathrm{Fe}, \mathrm{Mg}$ e $\mathrm{Mn}$ em biofilme e água de um córrego urbano. Os dados foram coletados, na microbacia do córrego São Gonçalo/Cuiabá/MT, em dois pontos amostrais (nascente e foz), no período de novembro/2014 a maio/2015. Considerando a média dos valores encontrados para metais, nota-se que a maior concentração ocorreu no biofilme, tal fato, pode estar relacionado ao tempo de exposição do substrato no corpo hídrico e o acúmulo na matriz exopolissacarídica. A ordem dos níveis de metais com referência aos valores médios foi igual para o biofilme em ambos os locais de coleta, entretanto observou-se uma distinção para a água. Na nascente a ordem de grandeza foi similar para a água e biofilme, apresentando a seguinte proporção $\mathrm{Mg}>\mathrm{Al}>\mathrm{Fe}>\mathrm{Mn}$. Na foz, os metais em água apresentaram a proporção de $\mathrm{Mg}>\mathrm{Fe}>\mathrm{Al}>\mathrm{Mn}$ e para o biofilme a sequência de $\mathrm{Mg}>\mathrm{Al}>\mathrm{Fe}>\mathrm{Mn}$. A comunidade microbiana foi maior no biofilme, entretanto os resultados obtidos nesse estudo mostraram que não houve correlação entre os metais potencialmente tóxicos e comunidade microbiana na forma planctônica e em biofilme, com exceção do $\mathrm{Mn}$ da água que se correlacionou negativamente com a comunidade microbiana do biofilme. Assim, os biofilmes têm se mostrado eficiente monitores de contaminação por metais.

\section{Detection of potentially toxic metals in biofilm and water of lotic environment}

\begin{abstract}
Biofilms have been shown to be good monitors of metal contamination as they provide rapid responses to environmental changes. The objective of this study was to evaluate the concentration of $\mathrm{Al}, \mathrm{Fe}, \mathrm{Mg}$ and $\mathrm{Mn}$ metals in biofilm and water of an urban stream. The data were collected, in the São Gonçalo/Cuiabá/MT stream microbasin, in two sampling points (source and mouth), from November/2014 to May/2015. Considering the average values found for metals, it is noted that the highest concentration occurred in the biofilm, this fact may be related to the exposure time of the substrate in the water body and the accumulation in the exopolysaccharide matrix. The order of metal levels with reference to the mean values was the same for the biofilm at both collection sites, however a distinction was made for water. At the spring the order of magnitude was similar for water and biofilm, presenting the following ratio $\mathrm{Mg}>\mathrm{Al}>\mathrm{Fe}>\mathrm{Mn}$. At the mouth, the metals in water had the ratio of $\mathrm{Mg}>\mathrm{Fe}>\mathrm{Al}>\mathrm{Mn}$ and for the biofilm the $\mathrm{Mg}>\mathrm{Al}>\mathrm{Fe}>\mathrm{Mn}$ sequence. The microbial community was larger in the biofilm, however the results obtained in this study showed that there was no correlation between the potentially toxic metals and the microbial community in the planktonic and biofilm forms, except for the water $\mathrm{Mn}$ that correlated negatively with the biofilm microbial community. Thus, biofilms have been shown to be efficient metal contamination monitors.
\end{abstract}

Keywords: Monitoring; Domestic Effluent; Environmental Pollution.

Topic: Engenharia Ambiental

Reviewed anonymously in the process of blind peer.
Received: $10 / 04 / 2018$

Approved: 24/05/2018

\section{Karine Paz de Almeida}

Universidade Federal de Mato Grosso, Brasil

http://lattes.cnpq.br/1548887400650422

karinepaz.qmc@gmail.com

\section{Maycon Ferreira Santos}

Universidade Federal de Mato Grosso, Brasil http://lattes.cnpq.br/7040677966938677

http://orcid.org/0000-0002-2205-2464

maycon443@gmail.com

Eliana Freire Gaspar Carvalho Dores

Universidade Federal de Mato Grosso, Brasil

http://lattes.cnpq.br/4094572237082106

http://orcid.org/0000-0001-5175-3537

elidores@gmail.com

\author{
Eduardo Beraldo de Morais (iD) \\ Universidade Federal de Mato Grosso, Brasi \\ http://lattes.cnpq.br/2910407574938593 \\ http://orcid.org/0000-0002-8505-4133 \\ beraldo_morais@yahoo.com.br \\ Danila Soares Caixeta (iD) \\ Universidade Federal de Mato Grosso, Brasil \\ http://lattes.cnpq.br/8314296350945580 \\ http://orcid.org/0000-0002-2036-1378 \\ danilacaixeta@gmail.com
}

\section{Referencing this:}

ALMEIDA, K. P.; SANTOS, M. F.; DORES, E. F. G. C.; MORAIS, E. B.; CAIXETA, D. S.. Detecção de metais potencialmente tóxicos em biofilme e água de ambiente lótico. Revista Ibero Americana de Ciências Ambientais, v.9, n.4, p.210-222, 2018. DOI: http://doi.org/10.6008/CBPC2179-6858.2018.004.0018 


\section{INTRODUÇÃO}

Nas últimas décadas, os recursos hídricos têm recebido uma grande carga de poluentes, que tem contribuído para modificações das suas características, fator este, desencadeado pelos usos múltiplos da água e pelas diversas atividades antrópicas, sejam elas domésticas, comerciais ou industriais. Cada uma dessas atividades gera poluentes característicos, substâncias, elementos ou resíduos tóxicos, que causam impactos negativos ao equilíbrio natural do corpo receptor.

Vários trabalhos têm voltado seu interesse para a quantificação da poluição por metais tóxicos na coluna de água e no sedimento (CHIBA et al., 2011; RIBEIRO et al., 2012), reunindo dados sobre o impacto ambiental e suas complexas relações com as atividades econômicas. Isso se deve, em parte, por possuírem potencial de bioacumulação e biomagnificação na cadeia alimentar, que corresponde à adsorção metabólica e a translocação ativa para dentro da célula resultando em acumulação celular (SILVA, 2010). Além disso, não são biodegradados, o que determina que permaneçam em ciclos biogeoquímicos globais, sendo o corpo hídrico seu principal meio de transporte.

Assim, estudos envolvendo o modo de ação dos metais em organismos aquáticos é fator chave para entender e determinar as consequências destes poluentes em nível de comunidade biológica, pois os organismos resumem a história recente de seu ambiente, refletindo os efeitos dos estressores ambientais. Deste modo, alguns organismos aquáticos têm sido utilizados como indicador biológico para monitorar o impacto de micropoluentes no ecossistema, tais como macroinvertebrados, peixes, macrófitas, algas e diatomáceas (ANCION et al., 2013). Entretanto, vários autores apontam a necessidade de buscar novas ferramentas que são ecologicamente mais relevantes e de fácil uso para avaliar a qualidade do ambiente e influência na comunidade aquática como um todo (TLILI et al., 2010). Entre estas novas ferramentas, os biofilmes têm se destacado, pois trazem respostas rápidas às alterações aquáticas, sendo um instrumento valioso, que reflete atributos biológicos, químicos ou físicos de uma condição ecológica (TLILI et al., 2010).

Os biofilmes são populações de microrganismos concentrados na interface líquido/sólido ou gás/líquido, embebidas em uma matriz orgânica composta de biopolímeros hidratados, tais como proteínas, exopolissacarídeos, glicolipídeos e DNA extracelular (KOECHLER et al., 2015). Em ambientes aquáticos podem ser classificados como: perifíton - desenvolvem em substrato submerso orgânico ou inorgânico, episamon biofilme que cresce sobre a areia ou epilíton - biofilme formado sobre rochas, constituídos de agregados complexos formados por bactérias, algas, protozoários e fungos (BATTIN et al., 2016).

Harrison et al. (2007) mencionam que os biofilmes microbianos podem ser usados para remediação de metais potencialmente tóxicos, uma vez que a matriz polimérica celular funciona como uma barreira aos metais, onde eles podem ser sequestrados, imobilizados, mineralizados e/ou precipitados (KOECHLER et al., 2015). Ademais, Koechler et al. (2015) mencionam que os microrganismos em biofilmes podem apresentar resistência ou tolerância a múltiplos metais, dependendo da diversidade microbiana, da concentração e especiação do metal e se são essenciais para suas atividades metabólicas. 
Vários estudos mostraram a sensibilidade de biofilme aos metais (FECHNER et al., 2011; TLILI et al., 2011; FABURÉ et al., 2015), no entanto, a interação entre os metais na água e biofilme não é bem compreendida (FABURÉ et al., 2015). Fechner et al. (2012a) observaram que o nível de tolerância de biofilme a cobre está relacionado com o grau de urbanização, demonstrando que os biofilmes se adaptam rapidamente a alterações ocorridas em seu entorno. Os biofilmes mantidos sob influência de metais, apresentam potencial elevado de bioacumulação e um declínio da diversidade de espécies, o que permite a identificação das espécies resistentes, que depende também do tipo de biofilme (TLILI et al.,2011; ARINI et al., 2012; FECHNER et al., 2012b). Ancion et al. (2013) sugerem que a análise da concentração de metais em biofilmes proporciona uma boa avaliação dos efeitos prejudiciais de contaminantes metálicos sobre a biota aquática.

Mesmo com vários estudos sobre o tema, ainda existem poucas pesquisas sobre as respostas de biofilme, em nível estrutural e funcional, à contaminação por metais pesados. No entanto, sabe-se que tal informação pode subsidiar a compreensão das respostas em nível de comunidades biológicas. Diante disso, o objetivo deste estudo foi verificar a presença de metais potencialmente tóxicos por meio de sua determinação em biofilme e água da microbacia do córrego São Gonçalo (Cuiabá/MT) de modo a avaliar o potencial de uso do biofilme como indicador da contaminação no ambiente estudado.

\section{METODOLOGIA}

\section{Área de estudo}

As amostras foram coletadas mensalmente durante um período de 07 meses (novembro/2014 a maio/2015) na microbacia do córrego São Gonçalo, em dois pontos amostrais, que compreendem os pontos mais próximos da nascente $\left(15^{\circ} 38^{\prime} 14^{\prime \prime} \mathrm{S} 56^{\circ} 0^{\prime} 38^{\prime \prime} \mathrm{W}\right)$ e sua foz $\left(15^{\circ} 38^{\prime} 44^{\prime \prime} \mathrm{S} 56^{\circ} 3^{\prime} 58^{\prime \prime} \mathrm{W}\right)$.

\section{Formação do biofilme}

Para promover a formação do biofilme, placas de vidro $(30 \times 10 \mathrm{~cm})$ acopladas a um suporte de madeira foram submersas, na posição vertical, nos dois pontos de amostragem, a $20 \mathrm{~cm}$ da superfície da água (Adaptado de BONET et al., 2014). Para o estabelecimento do biofilme no substrato, os suportes ficaram submersos por um período de 9 dias. Após esse período, com auxílio de um swab, foram coletadas amostras in situ de células sésseis, numa área de $1 \mathrm{~cm}$ de largura por $10 \mathrm{~cm}$ de comprimento (KASNOWSKI et al., 2010).

\section{Bactérias heterotróficas cultiváveis}

Para análise da água bruta foram coletados $200 \mathrm{~mL}$ da mesma e transferidos para frascos contendo tiossulfato de sódio $(0,1 \%)$ e EDTA (0,3\%). Para a análise das bactérias em biofilme, após 9 dias de exposição a $20 \mathrm{~cm}$ de profundidade da coluna de água, coletou-se amostras conforme metodologia supracitada, em seguida o swab foi submerso em solução salina $(0,85 \% \mathrm{NaCl})$ e acondicionada conforme APHA (2012). 
O desprendimento das células do swab foi realizado submetendo-o a agitação em agitador de tubos (modelo 251-Fanem) por 5 minutos. Após esse procedimento, realizou-se a técnica de diluição seriada (10 ${ }^{0}$ a $10^{-4}$ ) em frascos contendo $9 \mathrm{~mL}$ de água peptonada $(0,1 \%)$, sendo o número de células viáveis determinado em meio Ágar Nutriente (NutrientBroth, marca KASVI) (APHA, 2012). Após 24-48 horas de incubação a $37^{\circ} \mathrm{C}$ foi realizada a contagem das Unidades Formadoras de Colônias (UFC) e expresso em UFC/cm². Todo procedimento foi realizado em triplicata.

\section{Determinação de metais em água e biofilme}

A concentração de metais em água foi determinada de acordo com o método 3015 A - Microwave assisted acid digestion of aqueous samples and extracts (EPA, 2007). Para a digestão utilizou-se o digestor

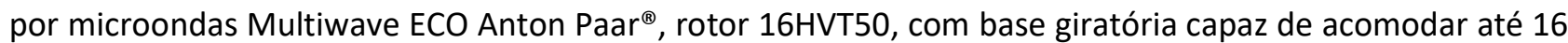
tubos de TFM. Foram transferidos $16 \mathrm{~mL}$ da amostra para o tubo de TFM com adição de 4,0mL de ácido nítrico concentrado (Chromoline ${ }^{\circledR}$ ) e 2,0mL de ácido clorídrico concentrado (Chromoline ${ }^{\circledR}$ ). Em seguida, o tubo foi fechado e colocado no forno de microondas com programa de aquecimento $\left(10 \mathrm{~min}, 170^{\circ} \mathrm{C}\right.$ no step 1 e 15 $\min , 0^{\circ} \mathrm{C}$ no step 2). As amostras de água preservadas foram digeridas com intuito de pré-concentrar as espécies metálicas de interesse e também mineralizar toda a matéria orgânica. As amostras foram analisadas em triplicata.

Para a quantificação da concentração dos metais Al, Fe, Mg e Mn utilizou-se espectrômetro de emissão óptica por plasma acoplado indutivamente (ICP-OES) Perkin Elmer, modelo Optima 8300, com nebulizador tipo seaspray com potência de frequência de $1450 \mathrm{~W}$, a um fluxo de gás argônio de 0,46L.min ${ }^{-1}$ e pressão do nebulizador de 200kPa. Os resultados foram apresentados como a média dos valores determinados e desvio padrão. O comprimento de onda utilizado para cada metal e os limites de quantificação (LQ) e limite de detecção (LD) são apresentados na Tabela 1.

Tabela 1: Comprimento de onda $(\mathrm{nm})$ utilizado para determinação de cada metal por ICP-OES, limite de quantificação (LQ) e limite de deteç̧ão (LD) do equipamento e do método para cada matriz.

\begin{tabular}{|c|c|c|c|c|c|c|}
\hline Metais & $\begin{array}{l}\text { Comprimento de } \\
\text { onda }(\mathrm{nm})\end{array}$ & $\begin{array}{l}\text { LD do equipamento } \\
\left.\text { (mg. } \mathrm{L}^{-1}\right)\end{array}$ & $\begin{array}{l}\text { LD do } \\
\text { método* } \\
\left(\mathrm{mg} \cdot \mathrm{L}^{-1}\right)\end{array}$ & $\begin{array}{l}\text { LD do } \\
\text { método** } \\
\left(\mu g . \mathrm{cm}^{-2}\right)\end{array}$ & $\begin{array}{l}\text { LQ do equipamento } \\
\left(\mathrm{mg} \cdot \mathrm{L}^{-1}\right)\end{array}$ & $\begin{array}{l}\mathrm{LQ} \text { do } \\
\text { método* } \\
\left(\mathrm{mg} \cdot \mathrm{L}^{-1}\right)\end{array}$ \\
\hline $\mathrm{Al}$ & 396,153 & 0,028 & 0,043 & 0,86 & 0,15 & 0,23 \\
\hline $\mathrm{Fe}$ & 259,939 & 0,0020 & 0,0030 & 0,060 & 0,010 & 0,015 \\
\hline $\mathrm{Mg}$ & 279,077 & 0,059 & 0,092 & 1,84 & 0,30 & 0,47 \\
\hline $\mathrm{Mn}$ & 396,153 & 0,0015 & 0,0020 & 0,050 & 0,010 & 0,015 \\
\hline
\end{tabular}

\section{Parâmetros físicos e químicos da água}

A temperatura da água $\left({ }^{\circ} \mathrm{C}\right)$, potencial hidrogeniônico, oxigênio dissolvido $\left(\mathrm{mg}^{\mathrm{L}} \mathrm{L}^{-1} \mathrm{O}_{2}\right)$ e condutividade elétrica $\left(\mu \mathrm{S} . \mathrm{cm}^{-1}\right)$ foram monitorados com sonda $\mathrm{HACH}^{\circledR} \mathrm{HQ} 40 \mathrm{~d}$, enquanto que para vazão $\left(\mathrm{m}^{3} . \mathrm{s}^{-1}\right)$ utilizouse Molinete fluviométrico. Os dados de precipitação pluviométrica foram obtidos da Estação Mestre Blombed, localizada na Universidade Federal de Mato Grosso - Cuiabá com as coordenadas geográficas 
1536'25,23" S e 5603'38,94" O, considerando-se apenas as precipitações que ocorreram no período de 9 dias, que antecederam a coleta.

\section{Análise estatística}

A normalidade e homocedasticidade de variâncias foram verificadas, respectivamente, pelo teste de Shapiro Wilk e Bartlett, e observou-se a não normalidade dos dados. Para correlacionar as variáveis físicas e químicas e os metais entre si e nos substratos e sua influência na comunidade de bactérias utilizou-se o teste de correlação de Spearman para amostras não pareadas. Foi avaliada a distribuição espacial das concentrações dos metais nos diferentes substratos, utilizando o teste de Wincoxon para amostras pareadas, comparando-se concentrações na nascente e foz. Para tanto, foi utilizado o programa SPSS 23.

\section{RESULTADOS}

\section{Parâmetros de qualidade da água da microbacia do São Gonçalo}

Os dados dos parâmetros físicos e químicos da qualidade da água da microbacia do São Gonçalo encontram-se na Tabela 2.

Tabela 2: Parâmetros físicos e químicos de qualidade da água do córrego São Gonçalo, entre novembro/2014 a maio/2015. Condutividade elétrica (CE), potencial hidrogeniônico $(p H)$, oxigênio dissolvido (OD), temperatura, $(T)$, vazão (Q), precipitação (Ppt).

\begin{tabular}{|c|c|c|c|c|c|c|c|}
\hline Coleta & Pontos & $\begin{array}{l}\text { CE } \\
(\mu \mathrm{S} / \mathrm{cm})\end{array}$ & $\mathrm{pH}$ & $\begin{array}{l}\text { OD } \\
\left.\text { (mg.L }{ }^{-1}\right)\end{array}$ & $\begin{array}{l}\mathrm{T} \\
\left({ }^{\circ} \mathrm{C}\right)\end{array}$ & $\begin{array}{l}Q \\
\left(\mathrm{~m}^{3} \cdot \mathrm{s}^{-1}\right)\end{array}$ & *Ppt (mm) \\
\hline \multirow[t]{2}{*}{ Novembro } & Nascente & 329 & 6,7 & 4,08 & 27,6 & 0,03 & \multirow[t]{2}{*}{60,20} \\
\hline & Foz & 402 & 7,03 & 4,51 & 28,9 & 2,00 & \\
\hline \multirow[t]{2}{*}{ Dezembro } & Nascente & 446 & 7,4 & 3,34 & 27,73 & 0,04 & \multirow[t]{2}{*}{33,30} \\
\hline & Foz & 467 & 7,69 & 5,2 & 28,35 & 3,43 & \\
\hline \multirow[t]{2}{*}{ Janeiro } & Nascente & 403 & 7,68 & 3,71 & 25,61 & 0,05 & \multirow[t]{2}{*}{71,50} \\
\hline & Foz & 493 & 7,83 & 4,78 & 26,38 & 4,00 & \\
\hline \multirow[t]{2}{*}{ Fevereiro } & Nascente & 420 & 7,95 & 6,91 & 30,43 & 0,05 & \multirow[t]{2}{*}{95,50} \\
\hline & Foz & 423 & 7,8 & 6,6 & 30,8 & 4,90 & \\
\hline \multirow[t]{2}{*}{ Março } & Nascente & 340 & 7,97 & 3,58 & 27,09 & 0,02 & \multirow[t]{2}{*}{8,90} \\
\hline & Foz & 518 & 8,25 & 4,3 & 28,93 & 3,00 & \\
\hline \multirow[t]{2}{*}{ Abril } & Nascente & 430 & 6,53 & 3,16 & 33,4 & 0,05 & \multirow[t]{2}{*}{23,9} \\
\hline & Foz & 434 & 6,58 & 3,77 & 32 & 1,00 & \\
\hline \multirow[t]{2}{*}{ Maio } & Nascente & 381 & 8,1 & 6,13 & 24,77 & 0,03 & \multirow[t]{2}{*}{11,10} \\
\hline & Foz & 447 & 8,6 & 4,68 & 25,39 & 0,98 & \\
\hline
\end{tabular}

* Dados da precipitação pluviométrica que ocorreu no período de 9 dias, que antecederam a coleta.

\section{Formação de biofilme em ambiente lótico}

Os resultados mostrados na Tabela 3 revelam que a concentração de células bacterianas foi superior no biofilme, quando comparado à presença destes microrganismos na água. Na Tabela 3, pode-se observar que a concentração de células no biofilme foi maior na foz. A tabela 4, mostra correlação de Spearman entre as bactérias heterotróficas do biofilme e água, bem como de metais potencialmente tóxicos e demais parâmetros físicos e químicas, na água e biofilme. O coeficiente de correlação de Spearman (rs) varia de 1 a -1 , sendo que os valores mais próximos de -1 indicam forte correlação inversa, os valores próximos de 1 indicam forte correlação direta e valores próximos de 0 apresentam fraca correlação (ARAÚJO et al., 2011). 
Tabela 3: Densidade de bactérias heterotróficas (BH) em água e biofilme em triplicata (a, b e c).

\begin{tabular}{|c|c|c|c|c|c|}
\hline \multirow[b]{2}{*}{ Coletas } & \multicolumn{3}{|l|}{ Água } & \multicolumn{2}{|l|}{ Biofilme } \\
\hline & Amostras & $\begin{array}{l}\text { BH Nascente } \\
\left(\text { Log UFC. } \mathrm{mL}^{-1}\right)\end{array}$ & $\begin{array}{l}\text { BH Foz } \\
(\text { Log UFC.mL-1) }\end{array}$ & $\begin{array}{l}\text { BH Nascente } \\
\left(\text { Log UFC } . \mathrm{cm}^{-2}\right)\end{array}$ & $\begin{array}{l}\text { BH Foz } \\
\left(\text { Log UFC } \mathrm{cm}^{-2}\right)\end{array}$ \\
\hline \multirow[t]{3}{*}{ Novembro } & $\mathrm{a}$ & 3,72 & 5,15 & 3,82 & 5,13 \\
\hline & $\mathrm{b}$ & 4,12 & 5,16 & 4,02 & 6,15 \\
\hline & $\mathrm{c}$ & 3,92 & 4,96 & 3,78 & 4,89 \\
\hline \multirow[t]{3}{*}{ Dezembro } & $\mathrm{a}$ & 4,26 & 5,10 & 4,98 & 4,88 \\
\hline & $\mathrm{b}$ & 4,27 & 4,89 & 5,26 & 4,94 \\
\hline & c & 4,45 & 4,72 & 5,14 & 5,11 \\
\hline \multirow[t]{3}{*}{ Janeiro } & $a$ & 5,17 & 4,03 & 6,28 & 5,72 \\
\hline & $\mathrm{b}$ & 5,19 & 4,25 & 6,24 & 5,94 \\
\hline & $\mathrm{c}$ & 5,11 & 4,17 & 6,29 & 6,01 \\
\hline \multirow[t]{3}{*}{ Fevereiro } & $a$ & 4,90 & 5,37 & 6,54 & 5,88 \\
\hline & $\mathrm{b}$ & 5,16 & 5,22 & 5,68 & 5,77 \\
\hline & $\mathrm{c}$ & 4,45 & 5,30 & 6,76 & 5,62 \\
\hline \multirow[t]{3}{*}{ Março } & $\mathrm{a}$ & 3,85 & 3,68 & 6,01 & 6,18 \\
\hline & $\mathrm{b}$ & 3,95 & 4,33 & 4,14 & 4,84 \\
\hline & $\mathrm{c}$ & 4,15 & 4,21 & 4,34 & 4,73 \\
\hline \multirow[t]{3}{*}{ Abril } & $a$ & 5,10 & 5,41 & 4,50 & 5,00 \\
\hline & $\mathrm{b}$ & 5,16 & 5,18 & 4,56 & 5,00 \\
\hline & c & 5,16 & 5,44 & 4,64 & 5,07 \\
\hline \multirow[t]{3}{*}{ Maio } & $a$ & 4,26 & 3,51 & 5,41 & 5,15 \\
\hline & $\mathrm{b}$ & 3,87 & 3,57 & 5,46 & 4,82 \\
\hline & c & 4,22 & 3,87 & 5,44 & 5,30 \\
\hline
\end{tabular}

Tabela 4: Correlação de Spearman entre bactérias heterotróficas Biofilme (BH B), bactérias heterotróficas água ( $B H A)$, alumínio biofilme $(A \mid B)$, alumínio água ( $A \mid A)$, ferro biofilme (Fe $B)$, ferro água (Fe $A)$, magnêsio biofilme (Mg $B$ ), magnêsio água $(\mathrm{Mg} A)$, manganês biofilme $(\mathrm{Mn} B)$, manganês água $(\mathrm{Mn} A)$, condutividade elétrica (CE), potencial hidrogeniônico $(\mathrm{pH})$, precipitação (Ppt), oxigênio dissolvido (OD), temperatura (T) e vazão (Q). (p<0,05). Valores em negrito indicam correlação satisfatória.

\begin{tabular}{|c|c|c|c|c|c|c|c|c|c|c|c|c|c|c|c|c|}
\hline & $\begin{array}{l}\text { BH } \\
\text { B } \\
\end{array}$ & $\begin{array}{l}\text { BH } \\
\text { A }\end{array}$ & $\begin{array}{l}\text { Al } \\
\text { B }\end{array}$ & $\begin{array}{l}\text { Al } \\
\text { A }\end{array}$ & $\begin{array}{l}\mathrm{Fe} \\
\mathrm{B} \\
\end{array}$ & $\begin{array}{l}\mathrm{Fe} \\
\mathrm{A}\end{array}$ & $\begin{array}{l}\text { Mg } \\
\text { B }\end{array}$ & $\begin{array}{l}\text { Mg } \\
\text { A }\end{array}$ & $\begin{array}{l}\text { Mn } \\
\text { Bio }\end{array}$ & $\begin{array}{l}\text { Mn } \\
\text { Ág }\end{array}$ & CE & pH & Ppt & OD & $\mathbf{T}$ & $\mathbf{Q}$ \\
\hline BH B & 1,00 & & & & & & & & & & & & & & & \\
\hline BH A & 0,18 & 1,00 & & & & & & & & & & & & & & \\
\hline Al B & 0,07 & 0,22 & 1,00 & & & & & & & & & & & & & \\
\hline Al A & $-0,19$ & 0,26 & 0,09 & 1,00 & & & & & & & & & & & & \\
\hline Fe B & $-0,12$ & 0,16 & 0,34 & $-0,11$ & 1,00 & & & & & & & & & & & \\
\hline Fe A & $-0,01$ & 0,57 & $-0,14$ & 0,31 & 0,07 & 1,00 & & & & & & & & & & \\
\hline $\mathrm{Mg} \mathrm{B}$ & $-0,41$ & $-0,31$ & 0,22 & $-0,04$ & 0,69 & $-0,11$ & 1,00 & & & & & & & & & \\
\hline $\mathrm{Mg} \mathrm{A}$ & $-0,24$ & 0,35 & 0,19 & 0,05 & $-0,25$ & 0,5 & $-0,28$ & 1,00 & & & & & & & & \\
\hline$M n B$ & $-0,33$ & $-0,1$ & $-0,1$ & 0,09 & 0,07 & $-0,24$ & 0,54 & $-0,38$ & 1,00 & & & & & & & \\
\hline $\mathrm{Mn} A$ & $-0,52$ & $-0,21$ & $-0,25$ & $-0,04$ & $-0,39$ & 0,12 & $-0,05$ & 0,54 & 0,05 & 1,00 & & & & & & \\
\hline CE & 0,05 & 0,1 & 0,11 & $-0,08$ & $-0,5$ & 0,07 & $-0,36$ & 0,35 & 0,01 & 0,59 & 1,00 & & & & & \\
\hline pH & 0,43 & $-0,59$ & $-0,25$ & $-0,21$ & $-0,58$ & $-0,36$ & $-0,2$ & $-0,19$ & 0,03 & 0,09 & 0,21 & 1,00 & & & & \\
\hline Ppt & 0,45 & 0,46 & 0,16 & 0,18 & 0,36 & 0,23 & $-0,05$ & $-0,43$ & $-0,06$ & $-0,73$ & $-0,12$ & $-0,32$ & 1,00 & & & \\
\hline$O D$ & 0,4 & $-0,05$ & $-0,16$ & 0,3 & $-0,17$ & $-0,16$ & $-0,08$ & $-0,58$ & 0,33 & $-0,35$ & 0,09 & 0,49 & 0,4 & 1,00 & & \\
\hline $\mathbf{T}$ & $-0,11$ & 0,64 & 0,07 & 0,42 & 0,07 & 0,36 & $-0,3$ & 0,42 & $-0,11$ & 0,14 & 0,18 & $-0,52$ & 0,18 & $-0,09$ & 1,00 & \\
\hline $\mathbf{Q}$ & 0,27 & 0,45 & 0 & 0,02 & $-0,38$ & 0,02 & $-0,51$ & $-0,04$ & 0,2 & 0,04 & 0,67 & 0,04 & 0,34 & 0,44 & 0,35 & 1,00 \\
\hline
\end{tabular}

\section{Concentrações de metais potencialmente tóxicos em água e biofilme e sua influência sobre as células microbianas.}

Neste estudo pode-se observar que as concentrações dos metais potencialmente tóxicos variaram em relação à água e biofilme, entretanto não houve diferença significativa entre os locais de amostragem (Tabela 5). 
Tabela 5: Concentração dos metais em água (A) $\left(\mathrm{mL} . \mathrm{L}^{-1}\right)$ e biofilme (B) $\left(\mu \mathrm{g} . \mathrm{cm}^{-2}\right)$, da microbacia do córrego São Gonçalo (Cuiabá/MT), nós períodos de novembro/2014 à maio/2015, em dois pontos amostrais.

\begin{tabular}{|c|c|c|c|c|c|c|c|c|c|}
\hline Coleta & Ponto & Al A & Al B & Fe $A$ & Fe B & Mg A & Mg B & Mn A & Mn B \\
\hline \multirow[t]{2}{*}{ Nov. } & Nasc. & 2,06 & 27,47 & 1,37 & 63,03 & 7,33 & 69,91 & 0,12 & 3,53 \\
\hline & Foz & 0,24 & $<0,86^{*}$ & 2,99 & 88,03 & 3,34 & 35,37 & 0,14 & 3,59 \\
\hline \multirow[t]{2}{*}{ Dez. } & Nasc. & 0,86 & $<0,86^{*}$ & 3,97 & 5,53 & 14,66 & 44,47 & 0,5 & 2,69 \\
\hline & Foz & 2,83 & $<0,86^{*}$ & 3,62 & 2,25 & 14,28 & $<0,092^{*}$ & 0,41 & 1,28 \\
\hline \multirow[t]{2}{*}{ Jan. } & Nasc. & 0,39 & 34,84 & 3,74 & 5,58 & 15,55 & 28,48 & 0,07 & $<0,002^{*}$ \\
\hline & Foz & 1,76 & 30,1 & 0,48 & 2,46 & 1,46 & 26,7 & 0,14 & 3,19 \\
\hline \multirow[t]{2}{*}{ Fev. } & Nasc. & 3,10 & 28,91 & 3,48 & 46,47 & 10,83 & 32,06 & 0,09 & 0,94 \\
\hline & Foz & 4,26 & $<0,86^{*}$ & 3,49 & 1,62 & 10,84 & $<0,092^{*}$ & 0,09 & 5,97 \\
\hline \multirow[t]{2}{*}{ Mar. } & Nasc. & 0,63 & $<0,86^{*}$ & 1,38 & 2,25 & 12,18 & $<0,092^{*}$ & 0,2 & 0,75 \\
\hline & Foz & 1,06 & 20,28 & 2,12 & 0,91 & 19,17 & $<0,092^{*}$ & 0,51 & 1,09 \\
\hline \multirow[t]{2}{*}{ Abr. } & Nasc. & 10,84 & 29,84 & 6,82 & 4,09 & 25,65 & 29,22 & 0,36 & 2,16 \\
\hline & Foz & 1,85 & 63,44 & 1,46 & 29,34 & 18,22 & 37,16 & 0,27 & 3,94 \\
\hline \multirow[t]{2}{*}{ Mai. } & Nasc. & 7,57 & 19,81 & 2,99 & 2,97 & 10,03 & 55,44 & 0,20 & 9,84 \\
\hline & Foz & $<0,043^{*}$ & 27,16 & 1,45 & 2,75 & 11,39 & 53,37 & 0,32 & 16,41 \\
\hline \multirow[t]{2}{*}{ Média } & Nasc. & 3,64 & 20,12 & 3,39 & 18,56 & 13,75 & 37,08 & 0,22 & 2,84 \\
\hline & Foz & 1,71 & 20,13 & 2,23 & 18,19 & 11,24 & 21,8 & 0,27 & 5,1 \\
\hline p-valor** & Ponto & 0,61 & 0,86 & 0,4 & 0,61 & 0,39 & 0,13 & 0,46 & 0,17 \\
\hline
\end{tabular}

*Menor que o LD

**Test de Wilcoxon de comparação dos resultados das concentrações dos metais na nascente e na foz (significância p <0,050)

\section{DISCUSSÃO}

\section{Parâmetros de qualidade da água da microbacia do São Gonçalo}

Os dados dos parâmetros físicos e químicos da qualidade da água da microbacia do São Gonçalo são subsídios para compreender o comportamento do sistema aquático e o grau de deterioração que ocorre, por meio das fontes pontuais e difusas de efluentes. As variáveis físicas e químicas podem ainda influenciar diretamente na concentração e especiação dos metais potencialmente tóxicos no corpo hídrico.

$\mathrm{O}$ pH das águas do córrego São Gonçalo variou de próximo à neutralidade a alcalino. Na nascente do córrego foram registrados valores menores do potencial hidrogeniônico $(\mathrm{pH})$ em relação a foz, com exceção do mês de fevereiro (Tabela 2). Para Marotta et al. (2008) o excesso de matéria orgânica contribui para reduzir o pH na água devido à liberação de gás carbônico durante a decomposição da matéria orgânica e da presença de compostos orgânicos ácidos. Assim, pode se pressupor que na nascente já ocorre lançamento de eflluente doméstico. Por outro lado, os valores mais alcalinos da foz, podem indicar enriquecimento da água por nitrogênio e fósforo neste ponto, pois estes compostos influenciam a taxa de fotossíntese do ecossistema, aumentando assim o pH (BUZELLI et al., 2013).

A temperatura da água esteve diretamente relacionada aos horários de coleta em todos os pontos, pressupondo que a mesma tenha aumentado com a temperatura do ar e com as condições climáticas, sendo os valores menores na nascente. Outro ponto importante que pode ter contribuído para os valores mais elevados na foz, são os lançamentos de efluente ao longo do córrego. Constatou-se correlação negativa da temperatura com o $\mathrm{pH}(-0,52)$.

A concentração de oxigênio dissolvido ficou abaixo de $5 \mathrm{mg} \mathrm{L}^{-1}$ na maioria das coletas indicando potencial efeito de lançamento de efluentes domésticos. Os valores de oxigênio dissolvido foram maiores na foz, podendo estar relacionados à vazão, que é significativamente mais alta, na parte final da bacia (Tabela 2), uma vez que quanto maior for esta variável mais irá contribuir para o processo de aeração, ocasionando 
elevação dos valores de OD. Outro ponto a considerar é que a falta de mata ciliar e consequentemente maior exposição a luz solar, que pode aumentar a atividade fotossintética interferindo na concentração de oxigênio.

A condutividade elétrica está diretamente relacionada à concentração total de íons, que pode ser proveniente de processos naturais do ambiente ou por fontes de esgoto sanitário e efluente industrial. Observou-se correlação positiva desta variável com a vazão $(0,67)$, ou seja, vazão mais elevada pode aumentar transporte de íons dissolvidos, por processo de lixiviação no solo, interferindo assim nos valores de condutividade elétrica. Os valores de condutividade elétrica foram elevados quando comparados com rios da região que normalmente apresentam CE menores do que $100 \mu \mathrm{S} . \mathrm{cm}^{-1}$ (Lima et al., 2015) fato que também deve estar relacionado ao lançamento de efluentes.

\section{Formação de biofilme em ambiente lótico}

A concentração de microrganismos aderidos a diferentes substratos é o que constitui um biofilme. Segundo Andrade et al. (1998) para ser considerado um biofilme, são necessários no mínimo de $10^{7}$ células aderidas por $\mathrm{cm}^{2}$, enquanto que Ronner et al. (1993) e Wirtanen et al. (1996) consideram biofilme o número de células aderidas de $10^{5}$ e $10^{3}$ por $\mathrm{cm}^{2}$, respectivamente. Neste estudo, adotou-se a concentração de $10^{3}$ UFC para ser considerado biofilme, conforme estabelecido por Wirtanen et al. (1996).

Embora seja notável na Tabela 3 que houve uma maior concentração de células bacterianas no biofilme, quando comparado à presença destes microrganismos na água, as análises estatísticas mostraram que não houve correlação entre a concentração de microrganismos na água e no biofilme, tal fato pode estar relacionado à constituição do biofilme, principalmente à presença de exopolissacarídeo que auxilia na imobilização de células.

Considerando os pontos de amostragem, nota-se que houve diferença em relação ao biofilme formado na nascente e na foz. Kokare et al. (2009) examinaram os biofilmes sob diferentes condições hidrodinâmicas, tais como fluxo laminar (onde existe um mínimo de agitação) e turbulento e verificaram que sua resposta era alterada para cada tipo de fluxo ao qual eram submetidos.

Supõe-se que o fluxo turbulento aumenta a adesão bacteriana e a formação de biofilmes, por aumento das colisões entre bactérias planctônicas e a superfície (DONLAN et al., 2002). Neste estudo, podese notar que na maioria dos meses analisados houve maior formação de biofilme na foz onde a vazão do córrego foi maior (Tabela 3).

$\mathrm{O}$ pH é consequência de uma série de fatores ambientais, incluindo geologia e hidrologia, podendo ter influência direta ou indireta sobre a comunidade do biofilme. A maioria dos biofilmes naturais forma-se em valores de $\mathrm{pH}$ próximos da neutralidade, e valores de $\mathrm{pH}$ superiores ou inferiores a 7 irão afetar o desenvolvimento e atividade do biofilme já que o $\mathrm{pH}$ tem um efeito preponderante no metabolismo microbiano. As bactérias heterotróficas da água se correlacionaram negativamente com o pH $(-0,59)($ Tabela 4) constatando que são variáveis inversamente proporcionais. Heino et al. (2014) verificaram em seu estudo que a diversidade bacteriana diminui com o aumento do pH. Chaves (2004) ressalta que o pH também afeta as propriedades superficiais dos microrganismos e das superfícies sólidas, podendo aumentar ou diminuir a 
repulsão eletrostática entre as duas entidades e, deste modo, interferir com o processo de adesão dos microrganismos às superfícies.

A temperatura é um fator determinante no desenvolvimento dos microrganismos, e pode influenciar na formação/adesão, na atividade e na composição do biofilme (TELLES, 2011; AZEVEDO et al., 2012). Em altas temperaturas ocorre a desnaturação das proteínas que compõem os microrganismos, consequentemente causando a diminuição da taxa de crescimento microbiano. A temperatura apresentou correlação positiva com as bactérias heterotróficas da água $(0,644)$ (Tabela 4). Hoellein et al. (2010) observaram que a temperatura pode regular a resposta do biofilme à captação de nutrientes, tendo encontrado a maior taxa de absorção de nutrientes na primavera, onde a temperatura foi maior.

\section{Concentrações de metais potencialmente tóxicos em água e biofilme e sua influência sobre as células microbianas}

Considerando a média dos valores encontrados para $\mathrm{Al}, \mathrm{Fe}, \mathrm{Mg}$ e $\mathrm{Mn}$, nota-se que a maior concentração dos metais estudados ocorreu no biofilme, fato este que pode estar relacionado ao tempo de exposição do substrato no corpo hídrico e o acúmulo na matriz exopolissacarídica (EPS) (Tabela 5). Os metais são facilmente acumulados e imobilizados pelo EPS devido às propriedades aniônicas da matriz, conferida pela presença de grupos carboxila, hidroxila, grupos amino, fosfato e outros grupos que podem se ligar aos íons metálicos (GONZÁLES et al., 2010; MORE et al., 2014).

A ordem das concentrações médias dos metais (Tabela 5) foi semelhante no biofilme e água, em ambos locais de coleta. Na nascente, a ordem de grandeza foi igual na água e no biofilme, apresentando a seguinte sequência $\mathrm{Mg}>\mathrm{Al}>\mathrm{Fe}>\mathrm{Mn}$. Na foz, os metais em água apresentaram a sequência de $\mathrm{Mg}>\mathrm{Fe}>\mathrm{Al}>\mathrm{Mn}$ e no biofilme a sequência de $\mathrm{Mg}>\mathrm{Al}>\mathrm{Fe}>\mathrm{Mn}$. O Mn como elemento menos abundante no solo (FADIGAS et al., 2002) foi o que esteve presente em menor concentração. O Fe (III) e o Al formam hidróxidos muito pouco

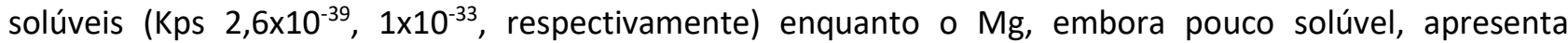
solubilidade bem maior do que estes outros dois metais ( $\left.\mathrm{Kps} 4 \times 10^{-12}\right)$ e os valores de $\mathrm{pH}$ das águas foram em sua maioria maiores do que 7, favorecendo a precipitação dos hidróxidos. Embora o $\mathrm{Fe}$ e o Al estejam presentes no solo em concentrações geralmente maiores que o Mg (FADIGAS et al., 2002; CORINGA et al., 2014) a sua maior solubilidade contribuiu para suas concentrações mais elevadas em todas as amostras. A similaridade das concentrações dos metais, nos pontos amostrais, pode estar relacionada às características químicas do solo da região e contaminações provenientes das ações antrópicas, pois as variáveis físicas e químicas da água evidenciam (Tabela 2), que desde a nascente o córrego recebe descarga de efluente doméstico. Sabe-se que algumas propriedades físicas e químicas, podem influenciar a dinâmica dos metais, tais como pH, temperatura, condutividade elétrica e OD (GONÇALVES et al., 2015).

Não foi observada correlação significativa entre as concentrações dos metais na água e no biofilme. Esse fato pode ser explicado pela diferença na estratégia de amostragem das duas matrizes. Enquanto o biofilme fica exposto por um período de 9 dias e acumula os metais neste período, a água foi coletada por 
amostragem pontual e instantânea, que representa somente o momento da coleta, enquanto a concentração dos metais pode ter variado de forma irregular e não previsível durante os 9 dias anteriores.

Analisando o ponto que compreende a nascente do córrego São Gonçalo, observa-se, maior concentração dos metais $\mathrm{Al}$, Fe e Mg em água no mês de abril, enquanto para o $\mathrm{Mn}$ a maior concentração foi no mês de dezembro. Observou-se correlação negativa do OD com o Mg $(-0,58)$ (Tabela 4). As menores concentrações dos metais na água da nascente foram encontradas nos meses de janeiro para o Al e Mn, nos meses de novembro para Fe e Mg. A condutividade elétrica (CE) está relacionada com a disposição dos metais, nos meses de novembro e janeiro, uma vez que nestes meses foram registrados os menores valores de CE. Observou-se correlação positiva entre a CE e Mn (0,59). Conforme Tlili et al. (2011) valores menores de CE na água correspondem a menor presença de ânions e cátions, consequentemente indicando menor entrada de metais no corpo hídrico.

No compartimento biofilme na nascente, com exceção do Mn cuja maior concentração ocorreu em maio, os metais tiveram um comportamento similar. A maior concentração de Al ocorreu em janeiro, de Fe e Mg em novembro. Observou-se maiores concentrações dos metais no biofilme, em contrapartida na água foram quantificados os menores valores, para o $\mathrm{Al}$, Fe e Mg. O acúmulo do metal no biofilme reflete a fração do metal na água (FABURÉ et al., 2015).

As concentrações dos metais na água da foz foram elevadas nos meses de março para o $\mathrm{Mg}$ e $\mathrm{Mn}$, e em fevereiro para o Al e dezembro para o Fe. Nota-se uma possível influência dos eventos de chuva, na concentração dos metais, pois os meses nos quais foram encontradas as maiores concentrações destes metais foram os de maior regime pluviométrico e chuva registrada nas últimas 24 horas, entretanto essa relação não foi observada para o $\mathrm{Mn}$ que teve correlação negativa com a precipitação $(-0,73)$, indicando que são grandezas inversamente proporcionais (Tabela 4). Bradác et al. (2010) observaram que as concentrações dos metais dissolvidos na corrente do Rio Altban aumentaram durante os eventos de chuva e atingiram concentrações máximas nos picos de chuva, provavelmente pela ressuspensão e dissolução do sedimento contaminado. Houve correlação positiva (Tabela 4) dos metais $\mathrm{Mg}$ e $\mathrm{Mn}$ na água $(0,54)$. Já as menores concentrações dos metais foram em janeiro para o Fe e $\mathrm{Mg}$ e para o $\mathrm{Al}$ em novembro e $\mathrm{Mn}$ em fevereiro, confirmando a influência do regime pluviométrico, pois nestes meses a precipitação acumulada foi mais elevada do que nos demais.

A concentração de $\mathrm{Al}, \mathrm{Mg}$ e $\mathrm{Mn}$ no biofilme da foz pode ter sido influenciada pelo regime pluviométrico, onde as maiores concentrações destes metais foram encontradas nos meses de abril e maio, que são caracterizados como os meses de declínio das chuvas e início do período de estiagem, em contrapartida a concentração de Fe foi maior em novembro. Houve correlação positiva do $\mathrm{Mg}$ e $\mathrm{Mn}$ no biofilme $(0,54)$. Observou-se correlação negativa do $\mathrm{Mg}$ no biofilme com a vazão $(-0,51)$ e positiva com o Fe do biofilme $(0,69)$. Bonet et al. (2014) observaram que a concentração dos metais $\mathrm{Mn}$, Fe e $\mathrm{Zn}$, foi afetada pela vazão, onde a menor vazão conduziu a elevada concentração de metais dissolvidos, consequentemente uma maior acumulação dos metais em biofilme. As menores concentrações dos metais no biofilme foram no 
mês de março para o Al, Fe e Mn, e para o Mg em janeiro. Observou-se correlação negativa do Fe no biofilme com o pH $(-0,58)$, o pH elevado pode influenciar na adsorção dos metais no biofilme.

Muitos estudos têm evidenciado que os biofilmes são capazes de incorporar os contaminantes, principalmente os metais traços (ARINI et al., 2012; KOECHLER et al., 2015). Os resultados obtidos nesse estudo mostraram que não houve correlação entre os metais potencialmente tóxicos e a concentração de células planctônicas e em biofilme, com exceção do $\mathrm{Mn}$ da água que se correlacionou negativamente com a comunidade microbiana do biofilme $(-0,52)$. Teitzel et al. (2003) realizaram um estudo para examinar o efeito dos metais sobre a comunidade de Pseudomonas aeruginosa em biofilme e água, e constataram uma maior resistência aos metais de 2 a 600 vezes nas células em biofilme, uma possível explicação para isto é que as substâncias poliméricas extracelulares do biofilme podem ser responsáveis pela proteção de células ao metal pesado, retardando a sua difusão dentro do biofilme.

Faburé et al. (2015) estudaram a resposta de biofilmes, em um rio com gradiente de contaminação urbana, e observaram que os biofilmes se mostraram sensíveis à contaminação por metais, mesmo quando o metal foi encontrado em baixa concentração na água. Esta relação também foi observada para o nosso estudo confirmam que os biofilmes são indicadores de contaminação difusa de metais.

\section{CONCLUSÕES}

O biofilme mostrou ser sensível em monitorar os metais analisados, sendo detectado na maioria do período estudado. Os biofilmes são muitas vezes mais resistentes quando comparados às células planctônicas, essa eficiência os tornam adequados para biomonitorar metais. A análise de metais em água usando amostras instantâneas pode não refletir a realidade do ecossistema quanto à presença de metais pesados, uma vez que os mesmos estão presentes normalmente em descargas intermitentes e em pequenas concentrações, que podem ou não coincidir com o momento da coleta das amostras. No entanto o estudo confirma que biofilmes têm grande potencial para ser utilizado como indicador biológico, pois foram eficientes como indicadores da presença de dos metais.

\section{REFERÊNCIAS}

ANCION, P.; LEAR, G.; DOPHEIDE, A.; LEWIS, G. D.. Metal concentrations in stream biofilm and sediments and their potential to explain biofilm microbial community structure. Environmental Pollution, v.173, p.117-124, 2013. DOI: http://doi.org/10.1016/j.envpol.2012.10.012

ANDRADE, N. J.; BRIDGEMAN, T. A.; ZOTTOLA, E. A.. Bacteriocidal activity of sanitizers against Enterococcus faecium attached to stainless steel as determined by plate count and impedance methods. Journal of Food Protection, v.61, n.7, p.833-838, 1998. DOI: http://doi.org/10.4315/0362-028X-61.7.833

APHA. American Public Health Association /AWWA -

American Water Works Association \& WPCF/Water Pollution Control Federation. Standard Methods. 22 ed. Washington: APHA, 2012.
ARAÚJO, G. C.; ZEILHOFER, P.. Padrões espaciais da qualidade da água na Bacia do Rio Cuiabá e Rio São Lourenço - Mato Grosso. Hygeia, Revista Brasileira de Geografia Médica e da Saúde, Uberlândia, v.7, n.13, p.5570, 2011.

ARINI, A.; FEURTET-MAZEL, A.; MAURY-BRACHET, R.; POKROVSKY, O.S.; COSTE, M.; DELMAS, F.. Recovery potential of periphytic biofilms translocated in artificial streams after industrial contamination ( $\mathrm{Cd}$ and $\mathrm{Zn}$ ). Ecotoxicology, v.21, p.1403-1414, 2012. DOI: http://doi.org/10.1007/s10646-012-0894-3

AZEVEDO, N. F.; CERCA, N.. Biofilmes: na saúde, no ambiente, na indústria. Porto: Publindústria, 2012.

BATTIN, T. J.; BESEMER, K.; BENGTSSON, M. M.; ROMANI, A. M.; PACKMANN, A. I.. The ecology and biogeochemistry of 
stream biofilms. Nature Reviews Microbiology, v.14, p.251263, 2016. DOI: http://doi.org/10.1038/nrmicro.2016.15

BONET, B.; CORCOLL, N.; TLILI, A.; MORIN, S.; GUASH, H.. Antioxidant enzyme activities in biofilms as biomarker of $\mathrm{Zn}$ pollution in a natural system: An active bio-monitoring study. Ecotoxicology and Environmental Safety, v.103, p.8290, 2014. DOI: http://doi.org/10.1016/j.ecoenv.2013.11.007

BRADÁC, P.; WAGNER, B.; KISTLER, D.; TRABER, J.; BEHRA, R.. Cadmium speciation and accumulation in periphyton in a small stream with dynamic concentration variations. Environmental Pollution, v.158, n.3, p.641-648, 2010. DOI: http://doi.org/10.1016/j.envpol.2009.10.031

BUZELLI, G. M.; CUNHA-SANTINO, M. B.. Análise e diagnóstico da qualidade da água e estado trófico do reservatório de Barra Bonita (SP). Revista Ambiente \& Água, Taubaté, v.8, n.1, p.186-205, 2013. DOI: http://doi.org/10.4136/ambi-agua.930

CHAVES, L. C. D.. Estudo da cinética de formação de biofilmes em superfícies em contato com água potável. Dissertação (Mestrado em Tecnologia do Ambiente) Universidade do Minho, Braga, 2004.

CHIBA, W. A. C.; PASSERINI, M. D.; BAIO, J. A. F.; TORRES, J. C.; TUNDISI, J. G.. Seasonal study of contamination by metal in water and sediment in a sub-basin in the southeast of Brazil. Brasilian Journal of Biology, São Carlos, v.71, n.4, 2011. DOI: http://doi.org/10.1590/S1519$\underline{69842011000500004}$

CORINGA, E. A. O.; COUTO, E. G.; TORRADO, P. V.. Geoquímica de solos do Pantanal Norte, Mato Grosso. Revista Brasileira de Botânica, v.38, n.6, p.1784-1793, 2014. DOI: http://doi.org/10.1590/S0100-06832014000600013

DONLAN, R. M.; COSTERTON, J. W.. Biofilms: survival mechanisms of clinically relevant microorganisms. Journal Clinical of Microbiology, v.15, n.2, p.167-93, 2002.

EPA. Method 3015A: Microwave assisted acid digestion of aqueous samples and extracts. Washington, 2007.

FABURÉ, J.; DUFOR, M.; AUTRET, A.; UHER, E.; FECHNER, L. C.. Impact of an urbanmulti-metal contamination gradient: Metal bioaccumulation and tolerance of river biofilms collected in different seasons. Aquatic Toxicology, v.159, p.276-289, 2015. DOI:

http://doi.org/10.1016/j.aquatox.2014.12.014

FADIGAS, F. S.; AMARAL SOBRINHO, N. M. B.; MAZUR, N.; ANJOS, L. H. C.; FREIXO, A. A.. Concentrações naturais de metais pesados em algumas classes de solos brasileiros. Bragantia, Campinas, v.2, n.2, p.151-159, 2002. DOI: http://doi.org/10.1590/S0006-87052002000200008

FECHNER, L. C.; GOURLAY-FRANCE, C.; TUSSEAU-VUILLEMIN, $M$. H.. Low exposure levels of urban metals induce heterotrophic community tolerance: a microcosm validation. Ecotoxicology, v.20, n.7, p.793-802, 2011. DOI: http://doi.org/10.1007/s10646-011-0630-4

FECHNER, L. C.; DUFOUR, M.; GOURLAT-FRANCE, C.. Pollution induced community tolerance of freshwater biofilms: measuring heterotrophic tolerance to $\mathrm{Pb}$ using an enzymatic toxicity test. Ecotoxicology, v.21, n.8, p.21232131, 2012a. DOI: http://doi.org/10.1007/s10646-012-0964$\underline{6}$

FECHNER, L. C.; VERSACE, F.; GOURLAY-FRANCE, C.; TUSSEAU-VUILLEMIN, M. H.. Adaptation of copper community tolerance levels after biofilm transplantation in an urban river. Aquatic Toxicology, v.106-107, p.32-41, 2012b. DOI: http://doi.org/10.1016/j.aquatox.2011.09.019

GONÇALVES, P. E. R. S.; OLIVEIRA, A. P.; FANTIN-CRUZ, I.; ZEILHOFER, P.; DORES, E. F. G. C.. Distribuição espacial de metais potencialmente tóxicos em água superficial nas bacias dos rios Cuiabá e São Lourenço - MT. Revista Brasileira de Recursos Hídricos, v.20, n.1, p.157-168, 2015.

GONZÁLEZ, A. G.; SHIROKOVA, L. S.; POKROVSKY, O. S.; EMNOVA, E. E.; MARTÍNEZ, R. E.; SANTANA-CASIANO, J. M.; GONZÁLEZ_DÁVILA, M.; POKROVSKI, G. S.. Adsorption of copper on Pseudomonas aureofaciens: Protective role of surface exopolysaccharides. Journal of Colloid and Interface Science, v.350, n.1, p.305-314, 2010. DOI: http://doi.org/10.1016/j.jcis.2010.06.020

HARRISON, J. J.; CERI, H.; TURNER, R. J.. Multimetal resistance and tolerance in microbial biofilms. Nature Reviews Microbiology, v.5, n.12, p.928-938, 2007. DOI: http://doi.org/10.1038/nrmicro1774

HEINO, J.; TOLKKINEN, M.; PIRTTILA, M.; AISALA, H.; MYKA, H.. Microbial diversity and community-environment relationships in boreal streams. Journal of Biogeography, v.41, n.12, p.2234-2244, 2014. DOI: http://doi.org/10.1111/jbi.12369

HOELLEIN, T. J.; TANK, J. L.; KELLY, J. J.; ROSI-MARSHALL, E. J.. Seasonal variation in nutrient limitation of microbial biofilms colonizing organic and inorganic substrata in streams. Hydrobiologia, v.649, n.1, p.331-345, 2010. DOI: http://doi.org/10.1007/s10750-010-0276-x

KASNOWSKI, M. C.; MANTILLA, S. P. S.; OLIVEIRA, L. A. T.; FRANCO, R. M.. Formação de biofilme na indústria de alimentos e métodos de validação de superfícies. Revista Científica Eletrônica de Medicina Veterinária, n.15, 2010.

KOECHLER, S.; FARASIN, J.; CLEISS-ARNOLD, J.; ARSÈNE, P.. Toxic metal resistance in biofilms: diversity of microbial responses and their evolution. Research in Microbiology, v.166, n.10, p.764-773, 2015. DOI: http://doi.org/10.1016/j.resmic.2015.03.008

KOKARE, C. R.; CHAKRABORTY, S.; KHOBADE, A. N.; MAHADIK, K. R.. Biofilms: importance and applications. Indian Journal Biotechnology, v.8, p.159-168, 2009. DOI: http://doi.org/10.5772/61499

LIMA, C. R. N.; ZEILHOFER, P.; DORES, E. F. G. C.; FANTINCRUZ, I.. Variabilidade espacial da Qualidade de Água em Escala de Bacias - Rio Cuiabá e São Lourenço, Mato Grosso. Revista Brasileira de Recursos Hídricos, v.20, n.1, p.169-178, 2015. DOI: http://doi.org/10.21168/rbrh.v20n1.p169-178

MAROTTA, H.; SANTOS, R. O.; ENRICH-PRAST, A.. Monitoramento limnológico: um instrumento para a conservação dos recursos hídricos no planejamento e na 
gestão urbano-ambientais. Ambiente \& Sociedade, Campinas, v.11, n.1, p.67-79, 2008

MORE, T. T.; YADAV, J. S. S.; YAN, S.; TYAGI, R. D.; SURAMPALLI, R. Y.. Extracellular polymeric substances of bacteria and their potential environmental applications. Journal of Environmental Management, v.144, p.1-25, 2014. DOI: http://doi.org/10.1016/j.jenvman.2014.05.010

RIBEIRO, E. V.; JUNIOR, A. P. M.; HORN, A. H.; TRINDADE, W. M.. Metais pesados e qualidade da água do Rio São Francisco no segmento entre Três Marias e Pirapora-MG: Índice de contaminação. Geonomos, v. 0, n.1, p.49-63, 2012. DOI: http://doi.org/10.18285/geonomos.v20i1.27

RONNER, A. B.; WONG, A. C. L.. Biofilm development and sanitizer inactivation of Listeria monocytogenes and Salmonella typhimurium on stainless steel and buna-n rubber. Journal of food Protection, v.56, n.9, p.750-758, 1993. DOI: http://doi.org/10.4315/0362-028X-56.9.750

SILVA, J. F.. Desenvolvimento de biofiltro para biossorção de cobre por Cladosporium cladosporioides (Fres.) de Vries. Tese (Doutorado) - Universidade Federal de Lavras, Lavras, 2010.

TEITZEL, G. M.; PARSEK, M. R.. Heavy metal resistance of biofilm and planktonic Pseudomonas aeruginosa.
Appliedand Environmental Microbiology, v.64, n.4 p.23132320, 2003. DOI: http://doi.org/10.1128/AEM.69.4.23132320.2003

TELLES, E. M.. A higienização na prevenção e no controle do biofilme: Uma revisão. Dissertação (Especialização em Ciências Veterinárias) - Universidade Federal do Rio Grande do Sul, Porto Alegre, 2011.

TLILI, A.; BÉRARD, A.; ROULIER, L. L.; VOLAT, B.; MONTUELLE, B.. $\mathrm{PO}_{4}^{-3}$ dependence of the tolerance of autotrophic and heterotrophic biofilm communities to copper and diuron. Aquatic Toxicology, v.98, n.2, p.165-177, 2010. DOI: http://doi.org/10.1016/j.aquatox.2010.02.008

TLILI, A.; CORCOLL, N.; BONET, B.; MORIN, S.; MONTUELLE, B.; BÉRARD, A.; GUASCH, H.. In situ spatio-temporal changes in pollution induced community tolerance to zinc in autotrophic and heterotrophic biofilm communities. Ecotoxicology, v.20, n.8, p.1823-1839, 2011. DOI: http://doi.org/10.1007/s10646-011-0721-2

WIRTANEN, G.; HUSMARK, U.; MATTILA-SANDHOLM, T. Microbial evaluation of the biotransfer potential from surfaces with Bacillus biofilms after rinsing and cleaning procedures in closed food-processing systems. Journal of Food Protection, v.59, n.7, p.727-733, 1996. 